\title{
Severe, self-limiting lactic acidosis and rhabdomyolysis accompanying convulsions
}

\author{
P.H. Winocour, A. Waise, G. Young and K.J. Moriarty \\ University Departments of Medicine and Clinical Biochemistry, Hope Hospital (University of Manchester School \\ of Medicine), Eccles Old Road, Salford M6 8HD, UK.
}

\begin{abstract}
Summary: A 26 year old man with no previous history of convulsions presented in status epilepticus and severe lactic acidosis. He regained consciousness and the acidosis resolved after several hours of conservative management without intravenous bicarbonate, but he developed severe myalgia associated with marked elevation of creatine kinase and moderate raised plasma creatinine levels which resolved spontaneously after 3 days.

Severe lactic acidosis and rhabdomyolysis may accompany status epilepticus, although they appear to be self-limiting without important sequelae.
\end{abstract}

\section{Introduction}

Lactic acidosis is generally regarded as a serious disorder, resulting from a variety of causes. We report on a man who developed severe lactic acidosis and rhabdomyolysis following convulsions, in whom there was a spontaneous recovery.

\section{Case report}

A 26 year old man, who had fractured his skull a year previously, presented in status epilepticus for 30 minutes, requiring treatment with intravenous diazepam. He had allegedly consumed his habitual 12 units of alcohol the previous night. On initial assessment, he was deeply comatose and his pupils were dilated but fully responsive to light. Apart from a tachycardia, vital signs were stable, and there was no focal neurological deficit. Arterial blood gases on air showed a marked metabolic acidosis $\left(\mathrm{pH} \mathrm{6.8,} \mathrm{PO}_{2}\right.$ $90 \mathrm{mmHg}, P_{C_{2}} 42 \mathrm{mmHg}$, bicarbonate $7 \mathrm{mmol} / \mathrm{l}$, base excess $-28 \mathrm{mmol} / \mathrm{l})$, and the anion gap was $38 \mathrm{mmol} / \mathrm{l}$ (sodium $149 \mathrm{mmol} / \mathrm{l}$, potassium $3.4 \mathrm{mmol} / \mathrm{l}$, chloride $107 \mathrm{mmol} / \mathrm{l}$. Transient elevations in blood glucose $(11.2 \mathrm{mmol} / \mathrm{l})$ and white cell count $\left(21.6 \times 19^{9} / 1\right)$ were recorded. Plasma lactate was $23.0 \mathrm{mmol} / \mathrm{l}$ (reference range $0.4-1.4 \mathrm{mmol} / \mathrm{l}$ ) and creatinine was elevated at $200 \mu \mathrm{mol} / 1$ (reference range $60-120 \mu \mathrm{mol} / \mathrm{l})$. No alcohol, salicylate, or other toxins were detectable in serum or urine, and a computed tomographic scan of the head revealed atrophy of the frontal lobes.

Correspondence: P.H. Winocour, M.B., M.R.C.P. Accepted: 30 November 1988
He was managed conservatively with oxygen and intravenous saline and recovered consciousness spontaneously 5 hours later, with an accompanying improvement in biochemistry (Figure 1). Thereafter he complained of myalgia and muscle weakness, particularly in his lower limbs, which lasted for 48 hours. Creatine kinase levels were markedly elevated at $29,430 \mathrm{IU} / \mathrm{l}$ (reference range $24-195 \mathrm{IU} / \mathrm{l}$ ), but fell the following day to $2000 \mathrm{IU} / \mathrm{l}$, when lactate dehydrogenase levels were slightly elevated at $650 \mathrm{IU} / 1$ (reference range 100-225 IU/1). Serum creatinine levels remained elevated at this stage $(214 \mu \mathrm{mol} / \mathrm{l})$, but subsequently fell to within the normal range (Figure 1). After 3 days the patient was free of symptoms and discharged. A subsequent electroencephalogram did not reveal any diagnostic features, and 6 months later, he had not experienced any further seizures. A diagnosis was made of posttraumatic epilepsy associated with lactic acidosis and rhabdomyolysis.

\section{Discussion}

Lactic acidosis and rhabdomyolysis are reported, although underdiagnosed, accompaniments of generalized convulsions. ${ }^{1,2}$ The degree of acidosis and muscle damage in the current report, however, is the greatest yet recorded in this situation and the former could have been interpreted as life threatening.' This might have led to inappropriate therapy with bicarbonate, ${ }^{3}$ since the acidosis resolved following supportive therapy with oxygen, intravenous saline and anticonvulsants. The lack of respiratory compensa- 

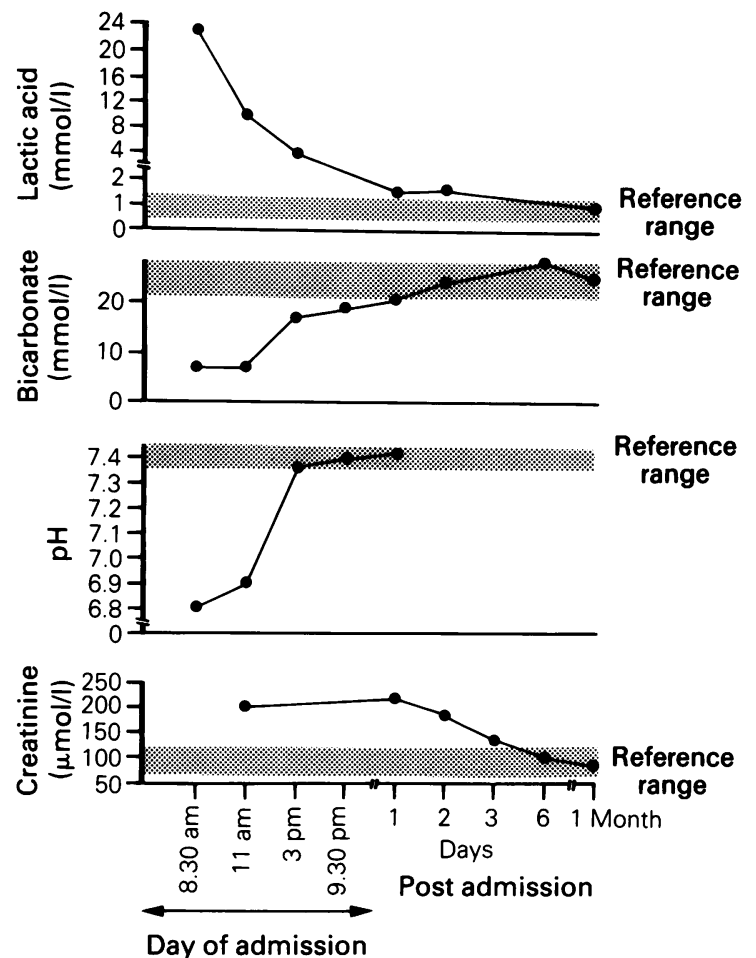

Figure 1 Serial changes in lactic acid, bicarbonate, $\mathrm{pH}$ and creatinine following admission with convulsions and severe lactic acidosis. tion for the metabolic acidosis in the present case wo also reported by Orringer et al. ${ }^{1}$ following a singe grand-mal seizure of 30 to 60 seconds duration, alat might be the consequence of suppression of the respiratory centre after the convulsion, although the use of diazepam in our patient could have compounded this effect. The low level of serum potassium in the current case is an important hallmark of metabolic acidosis secondary to lactic acidosis Alcohol intoxication was suspected in this case but not proven, although such severe lactic acidosis is not in fact expected with ethanol abuse. ${ }^{4}$ On the other hand prior alcohol consumption may have been implicated in the rhabdomyolysis, despite the absence of circulating ethanol at the time of admission. ${ }^{5}$

The mechanism of lactic acidosis following seizures is thought to be the consequence of local muscte hypoxia and increased production of pyruvic acid which is normally in equilibrium with lactic acid, Resolution is thought to occur predominantly due aerobic metabolism leading to reduced production of lactic acid and enhanced gluconeogenesis, although renal clearance may also be a factor. ${ }^{3}$ In this regard, the elevation of plasma creatinine and creatine kinase may reflect transient rhabdomyolysis-induced ren impairment. ${ }^{5,6}$ which could have delayed the return if serum lactic acid levels to normal for more than 2 days

It would appear that whilst severe lactic acidosisaing extensive muscle damage can accompany status epilepticus, these disturbances may be self-lim and do not require specific corrective therapy.

5. Gabow, P.A., Kaehny, W.D. \& Kelletter, S.P. Th spectrum of rhabdomyolysis. Medicine (Baltimore) 1989 61: $141-152$.

6. Ledingham, J.G.G. Nephrology: acute renal failure. Iñ Weatherall, D.J., Ledingham, J.G.G. \& Warrell, D.G. (eds) Oxford Textbook of Medicine, Vol. II, 2nd Ed Oxford University Press, Oxford 1985, 18: 131.

3. Kreisberg, R.A. Lactate homeostasis and lactic acidosis. Ann Int Med 1980, 92: 227-237.

4. Fulop, M., Bock, J., Ben-Ezra, J., Antony, M., Danzig, J. \& Gage, J.S. Plasma lactate and 3-hydroxybutyrate levels in patients with acute ethanol intoxication. Am J Med 1986, 80: $191-194$. 